American Journal of Pharmaceutical Education 2016; 80 (4) Article 57.

\title{
STATEMENT
}

\section{Entrustable Professional Activities for Pharmacy Practice}

\author{
Amy L. Pittenger, PharmD, PhD, ${ }^{a}$ Scott A. Chapman, PharmD, ${ }^{\text {a }}$ Caitlin K. Frail, PharmD, MS, ${ }^{a}$ \\ Jean Y. Moon, PharmD, ${ }^{a}$ Megan R. Undeberg, PharmD, ${ }^{b}$ Jordan H. Orzoff, $\mathrm{PhD}^{\mathrm{a}}$ \\ ${ }^{a}$ University of Minnesota College of Pharmacy, Minneapolis, Minnesota \\ ${ }^{\mathrm{b}}$ University of Minnesota College of Pharmacy, Duluth, Minnesota \\ Submitted August 26, 2015; accepted December 11, 2015; published May 25, 2016.
}

The profession of pharmacy is facing a shifting health system context that holds both opportunity and risk. If the profession of pharmacy is to advance, pharmacists must be recognized as a consistent member of the health care team in all clinical settings, contributing at the fullest extent of licensure and education. One part of achieving this broad goal is to implement a new way of defining and assessing pharmacy practice skills, such as entrustable professional activities (EPA). Assessment of professional tasks and practice activities with EPAs has been successfully implemented in medical education for assessing trainee preparation for practice. This EPA model is being applied to pharmacy education to develop an assessment framework across the advanced pharmacy practice experience (APPE) curriculum. The APPE course directors, practice faculty members, and the Office of Experiential Education collaboratively defined a set of universal EPAs critical for pharmacists in any practice setting and would be assessed in all practice experience types.

Keywords: Entrustable Professional activities, graduation performance assessment, curricular milestones, experiential education

\section{BACKGROUND}

The American Association of Colleges of Pharmacy's (AACP) Professional Affairs Standing Committee Report for 2014-2015, Producing Practice-Ready Pharmacy Graduates in an Era of Value-Based Healthcare, provided a thorough account of the challenges facing pharmacy practice and ensuring our students are ready for practice upon graduation. At the 2015 AACP Annual Meeting, during the Open Hearing of the Bylaws and Policy Development Committee, entrustable professional activities (EPAs) were discussed and debated, and AACP charged the 2015-2016 Academic Affairs Committee to critically examine the potential role of EPAs for pharmacy practice.

The University of Minnesota College of Pharmacy decided to use EPAs and a subsequent milestone strategy to define graduation standards for its program. The process of creating universal EPA statements was important in clarifying how we defined the generalist practitioner (as creating generalist practitioners is the mission of the college) and how to operationalize recently revised curriculum and competency statements into units of clinical practice. The EPA statements formed the basis of milestones for years one, two, and three

Corresponding Author: Amy Louise Pittenger, University of Minnesota College of Pharmacy, Room 5-110 WDH; 1332A, 308 Harvard St SE, Minneapolis, MN 55455. Tel: 612-625-7629. E-mail: alp@umn.edu and provided criteria for what would determine a passing grade for APPEs.

In addition, we used the EPA statements to frame a high stakes performance assessment required for graduation. Our rationale was to provide a learning roadmap for students, an internal mechanism for continuously evaluating our curriculum, and a documentation strategy to demonstrate progression across the program for the 2016 Accreditation Council for Pharmacy Education (ACPE) Standards. The EPA framework for assessment allowed us to specifically address Standard 24.3, on student achievement and readiness, by measuring educational outcomes for individual and aggregate performance at defined levels of performance.

The appropriateness of EPAs for pharmacy practice was not necessarily intuitive, and we struggled to translate the medicine example to our own context. But, now that we have achieved that, we believe it is an important strategy to ensure all pharmacy graduates are practice-ready. This statement regarding use of EPAs for pharmacy practice is a result of a year-long journey and concerned response to comments we heard at the standing committee session at the 2015 AACP Annual Meeting.

\section{USING EPAs FOR PHARMACY PRACTICE}

The competency-based approach to assessment of knowledge, skills, and attitudes in education is intended to ensure a standard minimum acceptable level of outcomes 


\section{American Journal of Pharmaceutical Education 2016; 80 (4) Article 57.}

for all graduates. ${ }^{1,2}$ By stating required competencies, educational programs move from a fixed-time, variableoutcome to a fixed-outcome, variable-time model. ${ }^{1,2}$ Theoretically, using competency-based assessment provides a mechanism to prevent students from graduating without first demonstrating the necessary combination of knowledge, skills, and attitudes to be effective clinicians. Programs that incorporate competency-based assessment require students to demonstrate competency rather than assume that competency is met at the end of the degree program. Demonstration of competency requires direct observation, which is central to the competencybased approach.

Competency-based education is not a new concept and is widely used across many educational programs, including pharmacy education. ${ }^{1}$ Pharmacy has used a competency-based approach to curriculum development for well over two decades and the 2016 ACPE Standards specifically uses the term competencies in framing the outcomes for pharmacy educational programs. ${ }^{3}$ While there is little argument over the importance of professional competence and the use of competencies to frame educational outcomes, operationalizing competency statements has led to confusion, including equating competency statements with learning or educational objectives or overly theoretical phrasing that lacks professional practice relevance. ${ }^{4}$

Medicine addressed the competency translation issue through the creation of performance statements regarding knowledge, skills, and attitudes assessed by the educator/preceptor and measured using a scale that describes various levels of trust, or EPAs. ${ }^{4}$ Trust is central to clinical practice and is also an important component of the assessment of learners within clinical environments by educators/preceptors. There must be trust that the learner has the necessary knowledge, skills, and attitudes to safely and effectively perform the professional practicerelated activities at the appropriate supervision levels, but also trust that the learner has appropriate self-awareness regarding personal limitations and knows when to ask for assistance. Professor Olle ten Cate, a leader in developing the EPA concept, clarifies the connection between competencies and EPAs this way: EPAs are not an alternative for competencies, but a means to translate competencies into clinical practice; competencies are descriptors of pharmacists [authors substituted pharmacists for physicians], EPAs are descriptors of work; EPAs usually require multiple competencies of an integrative, holistic nature. ${ }^{5}$

Competencies and EPAs are not mutually exclusive, and EPA statements require multiple competencies to perform EPAs. The Association of American Medical Colleges (AAMC) provides a helpful definition of EPAs, and the differences and similarities with competencies in their Core EPAs for Entering Residency report. ${ }^{6}$ In this report, they describe competency, EPA, and milestone, and we use these definitions for the college's EPA development. Competency is an observable ability of a health professional to integrate multiple components such as knowledge, skills, values, and attitudes. Since competencies are observable, they can be measured and assessed to ensure their acquisition. Entrustable professional activities are units of professional practice, defined as tasks or responsibilities that trainees are entrusted to perform unsupervised once they have attained specific sufficient competence. These activities are independently executable, observable, and measurable in their process and outcome, and, therefore, suitable for entrustment decisions. A milestone is a behavioral descriptor that marks a level of performance for a given competency.

Entrustable professional activities should be limited in number and provide extensive guidance for development, as well as a "level 5" of trust on a scale where level 1 is observation only and level 5 is providing supervision to learners (Table 1). ${ }^{5}$ Once EPAs are developed, backward milestones can be created that span the continuum from year one in the program into practice to provide a learning roadmap for students. ${ }^{5}$ The issue of measuring selfawareness is built into the level descriptions for each EPA statement. Table 2 provides an example of a rubric to assess milestones.

Another advantage of the EPA approach is that the designated level of trust is not given a judgmental label by the preceptor. Low levels of trust are expected and meet expectations for early learners. The levels describe what a learner is able to do along a continuum of skill development. This is in contrast to other scales that may label lower levels of performance as "poor" or "deficient." With the new approach, level 1 is expected to meet and meets expectations for early learners for most clinical practice competencies, and progression to higher levels of trust are demonstrated as they progress to meet graduation standards.

Medical practitioners began exploring EPAs 10 years ago with an approach based on sound educational theory. As pharmacy approaches the creation of universal EPAs (ie, demonstrated abilities expected of any pharmacist

Table 1. Pharmacy Practice Modified Levels of Entrustable Professional Activities (EPAs) ${ }^{5}$

\begin{tabular}{ll}
\hline Level 1 & Observe only, even with direct supervision \\
Level 2 & Perform with direct, proactive supervision \\
Level 3 & $\begin{array}{c}\text { Perform with reactive supervision (ie, on request } \\
\text { and quickly available) }\end{array}$ \\
Level 4 & $\begin{array}{l}\text { Supervise at a distance and/or post hoc } \\
\text { Level 5 }\end{array}$ \\
\hline
\end{tabular}




\section{American Journal of Pharmaceutical Education 2016; 80 (4) Article 57.}

Table 2. Rubric Example of One Milestone Entrustable Professional Activity (EPA) with Respective Level Descriptions

\begin{tabular}{l}
$\begin{array}{l}\text { Milestone EPA: Assess the pathophysiology of a patient's disease states/conditions } \\
\begin{array}{l}\text { Level of } \\
\text { Entrustment }\end{array} \\
\begin{array}{ll}\text { Level } 1 & \text { Description } \\
\text { I trust the student, with specific direction and direct supervision, to initiate a preliminary assessment of } \\
\text { common conditions seen within the practice setting. The student requires significant correction for } \\
\text { performance improvement. } \\
\text { I trust the student, with direct supervision and frequent correction, to assess common chronic conditions } \\
\text { seen within the practice setting. The student accepts feedback for performance improvement. } \\
\text { Level } 3 & \text { I trust the student, with limited correction, to assess common chronic conditions seen within the practice } \\
\text { setting. The student is self-directed and seeks guidance as necessary. }\end{array} \\
\text { I trust the student to completely and accurately assess common chronic conditions seen within the practice } \\
\text { setting as an independent practitioner (upon licensure). } \\
\text { Level } 5 \\
\text { I trust that the student has mastered the ability to completely and accurately assess common conditions } \\
\text { seen within the practice setting as an independent practitioner (upon licensure). The student is qualified } \\
\text { to give meaningful feedback to other learners. }\end{array}$ \\
\hline
\end{tabular}

independent of clinical setting), it is important to adhere to the principles outlined by ten Cate as closely as possible, including limiting the overall number of EPA statements and constantly returning to the idea that performing well as a pharmacist is defined as being entrustable to carry out all universal EPAs. By adhering as closely to principles as possible, the validity established by the approach in medicine will be maintained in the pharmacy context.

The pharmacy practice context is different from the medical practice context and requires adaptation of the EPA framework. For example, in defining the five levels of supervision for EPAs, a slight modification from ten Cate's version was made to provide language more appropriate to the pharmacy practice environment. Medicine and pharmacy differ in their expectations for independent practice upon graduation, so this difference alone will require modification. Table 1 provides a potential example of this type of modification. The EPA rubric describes what a student is able to do-as observed by a qualified practitioners or evaluators - at each level of each EPA, following the general descriptive model ranging from level 1 (observation and other tasks that do not require direct practice with a patient) to level 5 (supervision of others in practice) (Table 1).

Another deviation from ten Cate's EPA principles may be the inclusion of an EPA for areas of emphasized in the 2016 ACPE Standards, such as interprofessional collaboration, leadership, and lifelong learning. One of the tenets of the EPA literature is that EPAs usually require multiple competencies of an integrative, holistic nature. Also, determining whether someone has met the standard of the EPA at the appropriate level requires a direct observation assessment. It can be argued that attitude, interprofessional collaboration, leadership, and lifelong learning or self-directed learning strategies are competencies integral to several of the universal EPA statements and, therefore, EPA statements specific to either of these competencies are redundant and perhaps inappropriate. Despite this stated principle relating to EPA statements, medicine has an EPA for interprofessional collaboration. ${ }^{6}$

The charge of the 2015-2016 AACP Academic Affairs committee to critically examine this approach for pharmacy practice may lead to a core set of EPAs that define pharmacy practice nationally. Likely, individual institutions may create additional EPA statements that address unique pharmacy practice characteristics of their context and program priorities. After EPAs are developed, the next step is to establish expected milestones and assessment tools to measure progress. We propose four principles to guide expanding the rubric into a set of milestones and creating the assessment instruments: (1) EPAs should describe what a student is demonstrably able to do at that point in time; (2) Assessment of EPAs should be based on identifying expected behaviors rather than making a value judgment on the quality or deficiency of the student's performance; (3) Each pharmacy EPA develops at a different pace, culminating in the complete set of EPAs at level 5 for advanced practitioners performing at the peak of professional competency. For students (and early career practitioners), lower levels of EPAs are expected at the milestones at which they are assessed; (4) Simplicity and parsimony in measuring EPAs is essential in developing a system that balances validity with the necessity of engaging many busy professionals in performing observational assessments.

One approach to developing milestones is for faculty members, preceptors, and practicing pharmacists to calibrate each EPA by matching each of the five levels to the expected level of performance at a given milestone. A student beginning practice experiences might be expected 


\section{American Journal of Pharmaceutical Education 2016; 80 (4) Article 57.}

Table 3. Example of Milestone Entrustable Professional Activities (EPAs) and Potential Level of Entrustment Expected at the End of the Doctor of Pharmacy (PharmD) Year 2

\begin{tabular}{|c|c|c|c|}
\hline EPAs & Level 1 & Level 2 & Level 3 \\
\hline $\begin{array}{l}\text { Assess pathophysiology of a patient's disease } \\
\text { states/conditions. }\end{array}$ & & $\mathrm{X}$ & \\
\hline $\begin{array}{l}\text { Assess patient's past medical history, medication history and } \\
\text { experience, and allergy history. }\end{array}$ & & $\mathrm{X}$ & \\
\hline $\begin{array}{l}\text { Assess a patient's current medication regimen to ensure } \\
\text { medications are indicated, effective, safe, and convenient. }\end{array}$ & & & $\mathrm{X}$ \\
\hline Develop a patient-centered therapeutic plan. & & $\mathrm{X}$ & \\
\hline $\begin{array}{l}\text { Provide follow-up of a patient's medications evaluating continued } \\
\text { appropriateness of therapy and clinical outcomes. }\end{array}$ & & $\mathrm{X}$ & \\
\hline Provide therapeutic drug monitoring. & $\mathrm{X}$ & & \\
\hline $\begin{array}{l}\text { Document a patient-centered therapeutic plan and other patient-specific } \\
\text { clinical information. }\end{array}$ & & $\mathrm{X}$ & \\
\hline Work with interprofessional care team members. & & & $\mathrm{X}$ \\
\hline $\begin{array}{l}\text { Incorporate medical literature to provide evidence-based, best practice } \\
\text { clinical care. }\end{array}$ & $\mathrm{X}$ & & \\
\hline Provide medical information as written documentation. & & $\mathrm{X}$ & \\
\hline $\begin{array}{l}\text { Provide effective oral communication with patient and other health } \\
\text { care providers. }\end{array}$ & & & \\
\hline Exhibit professional behavior. & & & $\mathrm{X}$ \\
\hline
\end{tabular}

to be at level 3 on some EPAs while only at level 2 on others. This calibration could be accomplished using a technique such as Rasch modeling to identify the cutoff scores for each milestone. Individual pharmacy programs may find different milestones useful. For example, one program may want to test students' performance at the end of the doctor of pharmacy year 1, before the start of APPEs, and at graduation. Once the milestones are established and EPA cut-offs for each milestone validated, measurement tools can be developed to assess students at each milestone. As each EPA is essentially a descriptor of observable behaviors, such instruments could take the form of behavioral checklists, observers' rating scales, or even self-assessments or reflective tools. More detailed knowledge or skill assessments could also be developed based on the EPA descriptors or existing examinations [eg, the Pharmacy Curriculum Outcomes Assessment (PCOA), Objective Standardized Clinical Examinations (OSCEs)] might be mapped to EPA milestones.

Table 3 provides a potential example of how EPAs and milestones could align. Table 2 provides a more detailed description of each level given a specific EPA as an example. These descriptions for each level can essentially serve as the rubric. Transition from an existing evaluation strategy to the use of EPAs includes having a select group of faculty preceptors use both the existing evaluation tool and most current EPA tool, making adjustments as necessary. Preceptor development sessions are necessary to describe the EPA strategy and to explain how to use the EPA tool.

\section{CONCLUSION}

The American Association of Colleges of Pharmacy is exploring the use of EPAs to define pharmacy practice and translate ACPE 2016 Standards and competency statements. The EPA framework is based on sound educational theory and can be adapted to fit the pharmacy practice context. To have a meaningful discussion and debate surrounding this approach, pharmacy practitioners should use similar definitions and adhere as closely as possible to the theoretical principles that underpin this assessment strategy.

\section{REFERENCES}

1. Carraccio C, Wolfsthal SD, Englander R, Ferentz K, Martin C. Shifting paradigms: from Flexner to competencies. Acad Med. 2002;77(5):361-367.

2. Frank JR, Snell LS, ten Cate O, et al. Competency-based medical education: theory to practice. Med Teach. 2010;32(8):638-645. 3. Accreditation Council for Pharmacy Education (ACPE). Accreditation standards and key elements for the professional program in pharmacy leading to the doctor of pharmacy degree. https://www.acpe-accredit.org/pdf/Standards2016FINAL.pdf. Accessed March 13, 2015.

4. Ten Cate O. Entrustability of professional activities and competency-based training. Med Educ. 2005;39(12):1176-1177.

5. Ten Cate O. Nuts and bolts of entrustable professional activities. J Grad Med Educ. 2013;5(1):157-158.

6. Association of American Medical Colleges (AAMC). Core Entrustable Professional Activities (EPAs) for Entering Residency. http://members.aamc.org/eweb/upload/Core \%20EPA\% 20Curriculum\%20Dev\%20Guide.pdf. Accessed August 1, 2015. 